\title{
BMJ
}

\section{Sex, health, and years of sexually active life gained due to good health: evidence from two US population based cross sectional surveys of ageing}

\author{
Stacy Tessler Lindau, associate professor, ${ }^{1,2}$ Natalia Gavrilova, senior research associate ${ }^{1}$
}

\begin{abstract}
${ }^{1}$ Department of Obstetrics and Gynaecology, University of Chicago, 5841 S Maryland Avenue, MC2050, Chicago, IL 60637, USA, and Chicago Core on Biomeasures in Population-Based Aging Research, University of Chicago Centre on Demography and Economics of Aging

${ }^{2}$ Department of Medicine, Section of Geriatrics, University of Chicago Correspondence to: $\mathrm{S}$ Tessler Lindau slindau@uchicago.edu
\end{abstract}

Cite this as: $B M J$ 2010;340:с810 doi:10.1136/bmj.c810

\section{ABSTRACT}

Objectives To examine the relation between health and several dimensions of sexuality and to estimate years of sexually active life across sex and health groups in middle aged and older adults.

Design Cross sectional study.

Setting Two samples representative of the US population: MIDUS (the national survey of midlife development in the United States, 1995-6) and NSHAP (the national social life, health and ageing project, 2005-6).

Participants 3032 adults aged 25 to 74 (1561 women, 1471 men) from the midlife cohort (MIDUS) and 3005 adults aged 57 to 85 (1550 women, $1455 \mathrm{men}$ ) from the later life cohort (NSHAP).

Main outcome measures Sexual activity, quality of sexual life, interest in sex, and average remaining years of sexually active life, referred to as sexually active life expectancy.

Results Overall, men were more likely than women to be sexually active, report a good quality sex life, and be interested in sex. These gender differences increased with age and were greatest among the 75 to 85 year old group: $38.9 \%$ of men compared with $16.8 \%$ of women were sexually active, $70.8 \%$ versus $50.9 \%$ of those who were sexually active had a good quality sex life, and $41.2 \%$ versus $11.4 \%$ were interested in sex. Men and women reporting very good or excellent health were more likely to be sexually active compared with their peers in poor or fair health: age adjusted odds ratio $2.2(P<0.01)$ for men and $1.6(P<0.05)$ for women in the midlife study and 4.6 ( $\mathrm{P}<0.001)$ for men and 2.8 ( $\mathrm{P}<0.001)$ for women in the later life study. Among sexually active people, good health was also significantly associated with frequent sex (once or more weekly) in men (adjusted odds ratio 1.6 to 2.1), with a good quality sex life among men and women in the midlife cohort (adjusted odds ratio 1.7), and with interest in sex. People in very good or excellent health were 1.5 to 1.8 times more likely to report an interest in sex than those in poorer health. At age 30 , sexually active life expectancy was 34.7 years for men and 30.7 years for women compared with 14.9 to 15.3 years for men and 10 . 6 years for women at age 55 . This gender disparity attenuated for people with a spouse or other intimate partner. At age 55, men in very good or excellent health on average gained 5-7 years of sexually active life compared with their peers in poor or fair health. Women in very good or excellent health gained 3-6 years compared with women in poor or fair health.

Conclusion Sexual activity, good quality sexual life, and interest in sex were higher for men than for women and this gender gap widened with age. Sexual activity, quality of sexual life, and interest in sex were positively associated with health in middle age and later life. Sexually active life expectancy was longer for men, but men lost more years of sexually active life as a result of poor health than women.

\section{INTRODUCTION}

Human sexuality is increasingly recognised by doctors and policymakers as an important aspect of health and quality of life throughout the life course. ${ }^{1-3}$ Sexual activity has been associated with health benefits and longevity. ${ }^{4-6}$ Recent data from the US national social life, health and aging project (NSHAP) indicate that more than half of people aged 57-85 and about a third of those aged 75-85 are sexually active and that physical health is significantly correlated with sexual activity and many aspects of sexual function, independent of age. ${ }^{1}$

Since 2000, a focus on sexuality in older adults has been heavily driven by the availability of drugs to treat male erectile dysfunction. Effective treatment of this condition is likely to extend the duration of sexually active life for men and their partners as they age. Problems with sexual functioning are prevalent among older adults in the United States and other countries. ${ }^{17}$ About half of all sexually active men and women aged 57-85 in the United States report at least one bothersome sexual problem; one third report at least two. Yet doctors rarely address sexual concerns in older adults, particularly in women. ${ }^{1}$ As the older population grows in developed and developing nations, ${ }^{8}$ projecting the population structure of sexual activity is useful for anticipating need for public health resources, expertise, and services related to maintaining sexual function, regaining sexual function lost as a consequence of disease or treatments for common medical conditions that occur in later life, and preventing sexually transmitted diseases or risky sexual 
behaviour among older adults. Population estimates of sexual activity in later life can help motivate and inform the design of policies pertaining to sexual expression and rights among cognitively impaired and institutionalised elderly people. In addition, expectations about the duration of sexually active life may influence important health behaviours. For example, patients may be motivated to stop smoking or to adhere to drug regimens if the behaviour changes are expected to prolong or preserve a sexually active or sexually satisfying life.

Using two nationally representative datasets, we examined the association between sexuality (sexual activity and quality of sexual life) and global self rated physical health in middle aged and older men and women. We also estimated the average remaining years of sexually active life gained as a result of good health, using sexually active life expectancy, a new health expectancy indicator for clinical and public health application.

\section{METHODS}

The study populations were drawn from two large, publicly available and nationally representative recent health surveys with sufficiently large numbers of older respondents and comparable data on sexuality: the national survey of midlife development in the United States (MIDUS, or midlife cohort) and the national social life, health and aging project (NSHAP, or later life cohort).

The 1995-6 wave of MIDUS provides nationally representative data on adults aged 25 to 74 . Participants were selected by using a random digit dial sample of the non-institutionalised, English speaking population of the 48 conterminous United States. Participants completed a telephone interview and postal questionnaire. The response rate was $60.8 \%$, with 3032 respondents (1561 women, $1471 \mathrm{men}$ ) for both parts of the survey. Sampling weights correcting for differential probabilities of selection and non-response allow estimates from this sample to be generalisable to the United States population in terms of age, gender, race, and education. Details on the design, field procedures, and sampling weights of MIDUS have been described previously. ${ }^{9}$

The 2005-6 wave of NSHAP provides a nationally representative probability sample of community dwelling people aged 57-85, generated from households screened in 2004 across the United States. African-Americans, Latinos, men, and the oldest old (75 to 84 years at the time of screening in 2004) were oversampled. Interviews at home and collection of biomeasures were carried out in English and Spanish by professional interviewers, yielding 3005 respondents and a response rate of $75.5 \%$ weighted $(74.8 \%$ unweighted). Sampling weights account for differential probabilities of selection and differential non-response. Details on the design, field procedures, and sampling weights have been described previously. ${ }^{1}$ Both datasets are available to researchers through the National Archive of Computerized Data on Aging collection (www. icpsr.umich.edu/NACDA/). This analysis uses version 1.4 of the NSHAP dataset.

\section{Measures}

Self rated health is widely regarded as an appropriate measure of health, correlating well with other measures of morbidity and survival. ${ }^{1011}$ In both MIDUS and NSHAP, respondents were asked to rate their physical health using the standard five point scale responses to the question: "Would you say your health is excellent, very good, good, fair, or poor?" Both surveys included measures of partnership, sexual activity, sexual frequency, quality of sexual life, and interest in sex. Additionally, NSHAP assessed the degree to which sex was regarded an important part of life. Table 1 summarises and compares the items used in each survey.

NSHAP defined sexual activity for respondents as "any mutually voluntary activity with another person that involves sexual contact, whether or not intercourse or orgasm occurs." MIDUS defined sexual activity broadly as having "had sex with anyone." In MIDUS, $97.1 \%$ of men and $97.8 \%$ of women were identified as heterosexual, or "sexually attracted only to the opposite sex." In NSHAP, 96.4\% of men and $95.0 \%$ of women reported only heterosexual contacts during their lifetime.

Non-response to items in both surveys was low for measures of sexual activity, quality, and, in MIDUS, sexual interest $(0.3 \%$ to $5.1 \%)$. Non-response for the NSHAP questions about sexual interest ranged from $7.4 \%$ to $11.3 \%$. Non-response to questions on sexuality was higher among women compared with men and older people compared with younger people. For a random subset of NSHAP respondents, these questions were modularised to a questionnaire that was self completed after the face to face interview and returned by post to the investigators. In general, nonresponse to items was the same or higher for questions asked on this questionnaire compared with identical questions asked face to face. Overall, $84 \%$ of respondents returned the questionnaire. ${ }^{13}$

\section{Statistical analysis}

Distributions of race, education, marital status, self rated health, and sexuality variables are summarised separately by gender for MIDUS and NSHAP. We carried out analyses for each dataset separately to establish external validity of the findings.

We used logistic regression ${ }^{14}$ to model the likelihood of being sexually active, having a good quality sex life, and being interested in sex. These models included age group and self rated health (excellent or very good, good, and fair or poor) as covariates, which were fit separately by gender. Models for quality of sex life and frequency of sex were fit for participants who had a spouse or other intimate partner. We present results as odds ratios with $95 \%$ confidence intervals, indicating the multiplicative change in the odds of the 
Table 1|Comparison of health and sexuality measures used in national survey of midlife development in the United States (MIDUS) and national social life, health and ageing project (NSHAP)

\begin{tabular}{|c|c|}
\hline Characteristic & MIDUS (1995-6) \\
\hline Age range (years) & $25-74$ \\
\hline Self reported physical health & "Would you say your health is excellent, very good, good, fair, or poor?" \\
\hline Partnership & $\begin{array}{l}\text { Respondents who were married or cohabiting at time of survey, even if } \\
\text { they were not sexually active, were defined as having a partner }\end{array}$ \\
\hline Sexual activity & $\begin{array}{l}\text { Respondents who had had sex with at least one partner in previous six } \\
\text { months were considered to be sexually active }\end{array}$ \\
\hline Frequency of sex & $\begin{array}{l}\text { "Over the past six months, on average, how often have you had sex with } \\
\text { someone?" Responses ranged from: "never or not at all" to "two or more } \\
\text { times a week." Respondents having sex } 2-3 \text { times a month or more were } \\
\text { defined as having sex regularly }\end{array}$ \\
\hline \multicolumn{2}{|l|}{ Quality of sex life: } \\
\hline Positive physical quality & NA \\
\hline Positive emotional quality & NA \\
\hline Overall good quality & $\begin{array}{l}\text { "How would you rate the sexual aspect of your life these days?" Responses } \\
\text { ranged from } 0 \text {, "the worst possible situation," to } 10 \text {, "the best possible } \\
\text { situation." Individuals with a rating of } \geq 6 \text { were considered to have an } \\
\text { overall good quality of sexual life }\end{array}$ \\
\hline Interest in sex & $\begin{array}{l}\text { "How much thought and effort do you put into the sexual aspect of your } \\
\text { life?" Responses ranged from } 0 \text {, "none," to } 10 \text {, "very much." Respondents } \\
\text { with rating of } \geq 6 \text { were considered to be interested in sex }\end{array}$ \\
\hline
\end{tabular}

57-85

NSHAP (2005-6)

"Would you say your health is excellent, very good, good, fair, or poor?"

Respondents who were married or cohabiting at time of survey, even if they were not sexually active, were defined as having a partner

Respondents who had had sex with at least one partner in previous 12 months were considered to be sexually active*

"During the last 12 months, about how often did you have sex with [partner]?" Responses ranged from "once a month or less" to "once a day or more." Respondents having sex 2-3 times a month or more were defined as having sex regularly

"How physically pleasurable did/do you find your relationship with [partner] to be: extremely pleasurable, very pleasurable, moderately pleasurable, slightly pleasurable, or not at all pleasurable?" Individuals who reported their most recent relationship to be extremely or very pleasurable were defined as having a good quality of physical sexual life

"How emotionally satisfying did/do you find your relationship with [partner]: extremely satisfying, very satisfying, moderately satisfying, slightly satisfying, or not at all satisfying?" Individuals who reported their most recent relationship to be extremely or very satisfying were defined as having a good quality of emotional sexual life

Individuals having good quality of both physical and emotional components of sexual life were considered to have an overall good quality of sexual life

Estimated using the following question: "About how often do you think about sex?" with six variants ranging from "never" to "several times a day." Respondents who reported thinking about sex "one to a few times a week" or more were considered to be interested in sex

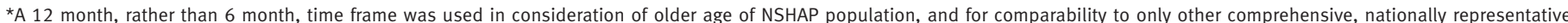
study of adult sexuality in the United States. ${ }^{12}$

outcome associated with a particular age or health category compared with those of the baseline category.

For all analyses we used weights to adjust for differential probabilities of selection and differential nonresponse. Standard errors were computed using the linearisation method, ${ }^{15}$ taking into account the stratification and clustering of the sample design. P values are two sided. Analyses were done using Stata software, release 9 .

\section{Calculation of sexually active life expectancy}

Population health is often summarised using measures of health expectancy. The concept of healthy life expectancy is typically based on self rated measures of overall or global health and is an effective tool for quantifying differences in health between populations. ${ }^{16}$ Related concepts include active life expectancy based on activities of daily living, disability-free life expectancy based on disability measures, dementia-free life expectancy, and others. ${ }^{16-21}$ These indicators project future health based on health or function at baseline. No such measures account for sexual function or sexual activity in projecting future health expectancy. We introduce a new health expectancy concept, sexually active life expectancy, defined as the average number of years remaining spent as sexually active, and investigate its relation to health among middle aged and older women and men.
We calculated sexually active life expectancy by Sullivan's method, using publicly available data from life tables and prevalence data on sexual activity to divide the number of person years into years with and without sexual activity. ${ }^{2223}$ We obtained US age and gender specific population and death counts for 1995 and 2004 from the human mortality database ${ }^{24}$ and we calculated age specific person years using standard methods for life tables. ${ }^{22}$ Prevalence data on sexual activity from MIDUS and NSHAP by age, gender, partnership status, and health status were used to calculate sexually active life expectancy. Life tables for 1995 (the year of enrolment of the midlife cohort) and 2004 (the year for which data were available closest to the 2005 enrolment of the later life cohort) were used in conjunction with MIDUS and NSHAP data, respectively. Using guidelines provided by the International Network on Health Expectancy ${ }^{22}$ we calculated standard errors and confidence intervals for sexually active life expectancy. The proportion of life spent as sexually active means the proportion of years of any sexual activity with a partner out of all remaining years of life.

Taking into account that a substantial proportion of the older population lives in institutions, we adjusted for no sexual activity among such a population. This adjustment decreased sexually active life expectancy measured at age 55 years by $2 \%$ for men and women. A sensitivity analysis, assuming a $20 \%$ rate of sexual activity among the institutionalised elderly population, had 
no effect on final estimates for sexually active life expectancy (data not shown). Data were taken from the 2000 US Bureau of Census table on age and gender specific proportions of the institutionalised population. ${ }^{25} \mathrm{We}$ fitted the age specific proportions of the institutionalised population older than age 60 with a two variable model of exponential growth using additional information on the age distribution of elderly people living in nursing homes. ${ }^{26}$

\section{RESULTS}

The key personal characteristics in the midlife and later life cohorts were similarly distributed and closely matched those from the 1995 and 2002 current population surveys, respectively. ${ }^{19}$ Men were more likely than women to be married; women were more likely than men to be widowed (table 2). The distribution of self rated health was similar for men and women; the prevalence of poor or fair health was higher in the later life cohort.

\section{Partnership}

Tables 3 and 4 show the distributions of partnership, sexual behaviour, and sexual attitudes, by age and gender, in MIDUS and NSHAP. Most men reported having a current partner: 79.8\% (95\% confidence interval $77.6 \%$ to $82.0 \%$ ) in the midlife cohort and $79.9 \%$
$(77.6 \%$ to $82.1 \%)$ in the later life cohort. The prevalence of partnership was stable across all age groups of men. In contrast, the prevalence of partnership among women declined steadily across age groups: $69.9 \%(95 \%$ confidence interval $67.5 \%$ to $72.4 \%)$ in the midlife cohort compared with $57.8 \%$ (55.0\% to $60.6 \%$ ) in the later life cohort. Only $38.5 \%$ of women compared with $72.0 \%$ of men aged $75-85$ had a partner (table 4).

\section{Sexual activity}

The prevalence of sexual activity in the midlife cohort declined across age groups for both sexes, but more so for women (table 3). By age 75, 16.8\% of women compared with $38.9 \%$ of men were sexually active (table 4 ). For respondents having a partner, however, these gender differences were much smaller and not statistically significant. Among sexually active respondents, the proportion engaging in sex once or more weekly declined across age groups but was similar among men and women in both cohorts (tables 3 and 4).

\section{Attitudes about sexual life}

Among sexually active middle aged respondents, about two thirds of men (69.7\%) and women (65.6\%) reported a good quality sex life (table 3 ). Only $51.8 \%$ of women in the later life cohort reported a good

Table 2 |Population distributions across demographic subgroups and self rated health in national survey of midlife development in the United States (MIDUS, 1995-6) and national social life, health and ageing project (NSHAP, 2005-6) cohorts, by gender. Values are numbers (percentages)

\begin{tabular}{|c|c|c|c|c|}
\hline \multirow[b]{2}{*}{ Characteristic } & \multicolumn{2}{|c|}{ MIDUS (midlife cohort) } & \multicolumn{2}{|c|}{ NSHAP (later life cohort) } \\
\hline & Men $(n=1471)$ & Women $(n=1561)$ & Men $(n=1455)$ & Women $(n=1550)$ \\
\hline \multicolumn{5}{|l|}{ Age (years): } \\
\hline $25-54$ & $1043(75.7)$ & $1048(70.8)$ & - & - \\
\hline $55-64^{*}$ & $263(12.3)$ & $337(17.4)$ & $528(43.6)$ & $492(39.2)$ \\
\hline $65-74$ & $164(12.0)$ & $175(11.8)$ & $547(35.0)$ & $545(34.8)$ \\
\hline $75-85$ & - & - & $380(21.4)$ & $513(26.1)$ \\
\hline \multicolumn{5}{|l|}{ Self reported race: } \\
\hline White & $1260(84.7)$ & $1324(83.2)$ & $1133(85.6)$ & $1162(84.4)$ \\
\hline Black & $75(9.7)$ & $126(12.7)$ & $224(9.2)$ & $285(10.8)$ \\
\hline Other & $88(5.6)$ & $71(4.1)$ & $94(5.3)$ & 99 (4.9) \\
\hline \multicolumn{5}{|l|}{ Education: } \\
\hline Less than high school graduate & $162(15.1)$ & $185(15.8)$ & $319(16.8)$ & $380(20.1)$ \\
\hline High school graduate & $370(33.0)$ & $471(38.2)$ & $343(24.3)$ & $450(29.5)$ \\
\hline College or associate's degree & $423(24.4)$ & $522(26.4)$ & $390(27.4)$ & $466(32.5)$ \\
\hline Bachelor's degree or higher & $514(27.6)$ & $383(19.5)$ & $403(31.5)$ & 254 (17.9) \\
\hline \multicolumn{5}{|l|}{ Marital status: } \\
\hline Married & $1046(73.8)$ & $895(63.8)$ & $1069(77.9)$ & $732(55.5)$ \\
\hline Living with partner & $75(6.0)$ & $69(6.2)$ & $30(1.9)$ & $30(2.4)$ \\
\hline Separated or divorced & $175(9.8)$ & $314(14.9)$ & $154(8.9)$ & $218(13.6)$ \\
\hline Widowed & $28(1.3)$ & $147(7.0)$ & $151(8.1)$ & $510(25.1)$ \\
\hline Never married & $147(9.1)$ & $136(8.2)$ & $51(3.2)$ & $60(3.4)$ \\
\hline \multicolumn{5}{|l|}{ Self rated health: } \\
\hline Poor or fair & $210(14.6)$ & $262(18.3)$ & $375(25.5)$ & $431(24.2)$ \\
\hline Good & $502(35.6)$ & $558(36.7)$ & $410(27.5)$ & $496(31.5)$ \\
\hline Very good or excellent & 759 (49.8) & $739(45.0)$ & $666(47.0)$ & $615(44.3)$ \\
\hline
\end{tabular}

Values are weighted to account for differential probabilities of selection and differential non-response.

*57-64 years in NSHAP. 
Table 3|Partnership status and characteristics of sexuality among participants of national survey of midlife development in the United States (MIDUS), by age. Values are percentages ( $95 \%$ confidence intervals) unless stated otherwise

\begin{tabular}{|c|c|c|c|c|c|}
\hline \multirow[b]{2}{*}{ Characteristic } & \multirow[b]{2}{*}{ No* } & \multicolumn{4}{|c|}{ Age groups (years) } \\
\hline & & All ages & $25-54$ & $55-64$ & $65-74$ \\
\hline \multicolumn{6}{|l|}{ Men } \\
\hline Married or living with partner & $1121 / 1471$ & 79.8 (77.6 to 82.0$)$ & 78.6 (76.0 to 81.3$)$ & 83.6 (78.7 to 88.5$)$ & 83.5 (77.6 to 89.4$)$ \\
\hline Sexually active during past six months: & $1209 / 1414$ & 87.2 (85.3 to 89.1$)$ & 91.2 (89.4 to 93.0$)$ & 86.3 (81.8 to 90.8$)$ & 62.1 (53.2 to 71.0$)$ \\
\hline Living with partner & $989 / 1075$ & 92.2 (90.4 to 94.0$)$ & 96.6 (95.2 to 98.0$)$ & 90.8 (87.0 to 94.7$)$ & $66.9(57.2$ to 76.6$)$ \\
\hline Not living with partner & $220 / 339$ & $67.5(61.8$ to 73.1$)$ & $71.4(65.3$ to 77.5$)$ & $64.0(47.7$ to 80.2$)$ & 38.1 (20.1 to 56.1$)$ \\
\hline Have sex once or more weekly among sexually active & $714 / 1209$ & $61.1(58.0$ to 64.1$)$ & $66.3(63.0$ to 69.7$)$ & 46.5 (38.8 to 54.1$)$ & $32.2(21.4$ to 43.1$)$ \\
\hline Overall good quality of sexual life among sexually active & $821 / 1206$ & 69.7 (66.9 to 72.6$)$ & $72.0(68.8$ to 75.2$)$ & $62.1(54.7$ to 69.5$)$ & $58.3(46.7$ to 69.9$)$ \\
\hline Interested in sex: & $931 / 1426$ & $66.4(63.7$ to 69.2$)$ & 70.5 (67.4 to 73.6$)$ & $62.0(55.1$ to 68.8$)$ & $44.6(35.5$ to 53.8$)$ \\
\hline Living with partner & $743 / 1087$ & 69.1 (66.1 to 72.2$)$ & 73.5 (70.1 to 76.9$)$ & 64.3 (56.8 to 71.8$)$ & $47.3(37.1$ to 57.5$)$ \\
\hline Not living with partner & $188 / 339$ & $55.6(49.5$ to 61.6$)$ & $59.2(52.4$ to 65.9$)$ & 50.3 (33.6 to 67.0$)$ & $30.8(14.1$ to 47.4$)$ \\
\hline \multicolumn{6}{|l|}{ Women } \\
\hline Married or living with partner & $964 / 1561$ & $69.9(67.5$ to 72.4$)$ & $72.6(69.7$ to 75.5$)$ & $67.8(62.3$ to 73.4$)$ & $57.6(49.2$ to 66.0$)$ \\
\hline Sexually active during past six months: & $1055 / 1505$ & 75.8 (73.5 to 78.2$)$ & $86.0(83.8$ to 88.2$)$ & 61.5 (55.4 to 67.5$)$ & $35.8(27.0$ to 44.6$)$ \\
\hline Living with partner & $836 / 934$ & 90.0 (87.8 to 92.1$)$ & 96.4 (95.0 to 97.8$)$ & $79.7(73.3$ to 86.0$)$ & $59.0(46.6$ to 71.4$)$ \\
\hline Not living with partner & $219 / 571$ & $42.4(37.5$ to 47.3$)$ & $58.2(52.2$ to 64.1$)$ & 22.1 (12.7 to 31.5$)$ & 3.7 (0.1 to 7.3$)$ \\
\hline Have sex once or more weekly among sexually active & $582 / 1055$ & 56.1 (52.8 to 59.5$)$ & $62.2(58.6$ to 65.9$)$ & 34.5 (26.8 to 42.1$)$ & 22.8 (10.3 to 35.2$)$ \\
\hline Overall good quality of sexual life among sexually active & $672 / 1051$ & $65.6(62.5$ to 68.8$)$ & 68.4 (64.9 to 71.8$)$ & 53.7 (45.7 to 61.7$)$ & 55.9 (39.9 to 71.8$)$ \\
\hline Interested in sex: & $737 / 1490$ & $52.8(49.9$ to 55.7$)$ & $61.8(58.5$ to 65.1$)$ & $38.2(32.1$ to 44.3$)$ & $17.5(10.3$ to 24.7$)$ \\
\hline Living with partner & $540 / 935$ & 59.3 (55.9 to 62.7$)$ & 67.5 (63.7 to 71.3$)$ & 44.5 (36.9 to 52.1$)$ & $23.2(12.7$ to 33.7$)$ \\
\hline Not living with partner & $197 / 555$ & 37.0 (32.2 to 41.9$)$ & 46.9 (40.8 to 53.0$)$ & 23.9 (14.7 to 33.0$)$ & 8.4 (0.7 to 16.2$)$ \\
\hline
\end{tabular}

Numbers and percentage estimates are weighted to account for differential probabilities of selection and differential non-response.

*Number who answered question affirmatively of total number of respondents to question. Numbers of respondents varies within survey as some declined to answer some questions.

quality sexual life compared with $71.1 \%$ of men, and this difference was statistically significant (table 4). Men were significantly more likely to report being interested in sex compared with women $(66 \%$ v $53 \%$ in the midlife cohort and $62 \% v 21 \%$ in the later life cohort). For men, interest in sex was relatively stable across all age groups and did not vary by partner status. For women, interest in sex dropped off significantly in the middle of the sixth decade and was much lower among those without partners.

\section{Cohort comparisons}

Both the midlife and the later life cohort included people aged 57-64 and 65-74. When these age groups were compared across the cohorts, surveyed 10 years apart, the distributions of prevalence estimate for partnership, sexual activity, sexual frequency, and good quality of sex life (among sexually active individuals) were highly consistent. Interest in sex among women in this age group surveyed 10 years apart was also stable $(17.5 \%$ in $1995,19.1 \%$ in 2005-6). In contrast, a significantly higher proportion (75.3\%) of men aged 57-64 in the later life cohort reported an interest in sex compared with only $44.6 \%$ of men of the same age surveyed 10 years earlier (midlife cohort; tables 3 and 4).

\section{Health and sexuality}

Health was strongly associated with having a partner, particularly for women, in the later life cohort (table 5). Sexual activity, particularly for men and for women in the later life cohort, was also positively associated with health (table 5). Among sexually active respondents, good health was significantly associated with frequent sex (once or more weekly) in men (adjusted odds ratio 1.6 to 2.1 ) and with a good quality sex life among men and women in the midlife cohort (1.7). People in very good or excellent health were 1.5 to 1.8 times more likely to report an interest in sex than those in poorer health.

\section{Sexually active life expectancy}

Table 6 summarises gender differences in sexually active life expectancy and the estimated proportion of remaining sexually active life at age 30 years (based on the midlife cohort) and age 55 years (based on the midlife and later life cohorts). Among all people at age 30, including those without a partner, sexually active life expectancy was about 10 years lower than demographic life expectancy for men (34.7 $v 44.8$ years) and nearly 20 years lower for women (30.7 $v 50$. 6 years). This translated to significant gender differences in the proportion of remaining lifetime spent as sexually active: $78 \%$ for men versus $61 \%$ for women. In contrast, among those with a partner at age 30 , sexually active life expectancy was higher for women compared with men (38.2 v36.7 years). Regardless, women with a partner were estimated to spend a smaller proportion of their remaining lifetime as sexually active as men owing to women's longer life expectancy. Both men and women reporting very good or excellent health had more years of sexually active life expectancy compared with people reporting fair or poor health. At age 
30 , men in very good or excellent health were projected to gain more years of life as sexually active $(6.4$ additional years) compared with women (4.8 years).

At age 55, sexually active life expectancy was 15 years for men and 10.6 years for women; the two datasets generated nearly identical estimates. For men at age 55 , sexually active life expectancy was $8-9$ years less than demographic life expectancy (14.9 $v 23$ years for the midlife cohort and $15.3 v 24.6$ years for the later life cohort); for women this difference was 17-18 years (10.6 $v 27.4$ years for the midlife cohort and $10.6 v 28$. 3 years for the later life cohort). Sexually active life expectancy was similar for men and for women with a partner at age 55 (15.9 to 16.9 and 15.6 to 16.2 years, respectively). At age 55 , men in very good or excellent health were projected to gain on average 5-7 years of life as sexually active compared with their peers in poor or fair health; women in very good or excellent health were projected to gain 3-6 years (table 5).

Figures 1 and 2 show the age pattern of life expectancy and sexually active life expectancy for men and women in the United States. Women had consistently higher demographic life expectancy at all ages, whereas men had consistently higher values for sexually active life expectancy. Wider differences were shown in sexually active life expectancy by health status for men compared with women at all age groups. The sexually active life expectancy curves for men and women reporting poor or fair health were similar. In contrast, in all but the oldest age group, men in very good or excellent health had significantly higher sexually active life expectancy than similarly healthy women.

\section{DISCUSSION}

This study used two nationally representative, population based cohorts to deepen an understanding of the relation between health and sexuality in middle and later life and to project population estimates of sexually active life expectancy, a new measure to quantify expectations about future sexual life. Using two datasets, the study affirmed a positive association between later life health and both sexual partnership and any sexual activity. In addition, a consistently strong association was found between good health and other domains of sexuality not previously linked to health in later life, including the frequency of sexual activity (weekly or more often) in men, a good quality sex life, and a higher interest in sex. Sexual activity, a good quality sex life, and interest in sex were higher for men than for women and this gender gap widened with age. Sexually active life expectancy was longer for men, but men lost more years of sexually active life as a result of poor health than women.

Partnership drives sexual activity, particularly in later life. Between $70 \%$ and $80 \%$ of men across all age

Table 4|Partnership status and characteristics of sexuality among participants of national social life, health and ageing project (NSHAP), by age. Values are percentages ( $95 \%$ confidence intervals) unless stated otherwise

\begin{tabular}{|c|c|c|c|c|c|}
\hline \multirow[b]{2}{*}{ Characteristic } & \multirow[b]{2}{*}{ No* } & \multicolumn{4}{|c|}{ Age group (years) } \\
\hline & & All ages & $57-64$ & $65-74$ & $75-85$ \\
\hline \multicolumn{6}{|l|}{ Men } \\
\hline Married or living with partner & $1099 / 1455$ & 79.9 (77.6 to 82.1$)$ & 84.2 (80.7 to 87.6$)$ & 79.3 (75.5 to 83.0$)$ & $72.0(67.1$ to 76.8$)$ \\
\hline Sexually active over past 12 months: & $906 / 1381$ & 68.7 (65.9 to 71.5$)$ & 84.4 (80.7 to 88.1 ) & $67.4(62.8$ to 72.0$)$ & 38.9 (33.1 to 44.6$)$ \\
\hline Living with partner & $765 / 1035$ & $76.2(73.3$ to 79.1$)$ & $90.5(87.3$ to 93.7$)$ & $73.9(69.1$ to 78.8$)$ & $46.3(39.1$ to 53.4$)$ \\
\hline Not living with partner & $141 / 346$ & 39.6 (33.7 to 45.6$)$ & $52.3(40.5$ to 64.0$)$ & $43.6(33.7$ to 53.4$)$ & 19.8 (11.7 to 27.8$)$ \\
\hline Have sex once or more weekly & $312 / 858$ & 34.8 (30.9 to 38.8 ) & 39.7 (33.6 to 45.8$)$ & $31.2(25.7$ to 36.7$)$ & $22.9(15.3$ to 30.4$)$ \\
\hline Positive physical quality of sex life & $743 / 892$ & 79.1 (76.5 to 81.7$)$ & 82.4 (78.3 to 86.6$)$ & 75.1 (70.8 to 79.4$)$ & 78.9 (74.1 to 83.8$)$ \\
\hline Positive emotional quality of sex life & $740 / 896$ & 79.0 (76.5 to 81.5$)$ & 81.0 (76.9 to 85.0$)$ & 75.9 (71.6 to 80.1$)$ & 80.1 (75.6 to 84.5$)$ \\
\hline Overall good quality of sex life & $678 / 892$ & 71.1 (68.3 to 74.0$)$ & $74.3(69.7$ to 79.0$)$ & $67.3(62.7$ to 72.0$)$ & $70.8(65.5$ to 76.1$)$ \\
\hline Interested in sex: & $779 / 1296$ & $62.0(58.9$ to 65.1$)$ & 75.3 (70.7 to 80.0$)$ & 58.1 (53.1 to 63.2$)$ & $41.2(35.2$ to 47.3$)$ \\
\hline Living with partner & $609 / 986$ & 63.3 (59.7 to 66.8$)$ & 76.7 (71.7 to 81.7$)$ & $56.3(50.7$ to 62.1$)$ & $43.7(36.3$ to 51.1$)$ \\
\hline Not living with partner & $170 / 310$ & $57.0(50.5$ to 63.5$)$ & 67.8 (55.6 to 80.0$)$ & 65.1 (55.1 to 75.1$)$ & $34.6(24.8$ to 44.4$)$ \\
\hline \multicolumn{6}{|l|}{ Women } \\
\hline Married or living with partner & $762 / 1550$ & $57.8(55.0$ to 60.6$)$ & 70.5 (66.0 to 74.9$)$ & 58.1 (53.4 to 62.8$)$ & $38.5(33.5$ to 43.5$)$ \\
\hline Sexually active over past 12 months: & $527 / 1493$ & 42.6 (39.6 to 45.6$)$ & $61.9(57.0$ to 66.8$)$ & 39.8 (34.9 to 44.8$)$ & $16.8(12.8$ to 20.9$)$ \\
\hline Living with partner & $466 / 724$ & 67.5 (63.7 to 71.2$)$ & 81.1 (76.4 to 85.8$)$ & $61.2(54.5$ to 67.9$)$ & $41.3(32.5$ to 50.1$)$ \\
\hline Not living with partner & $61 / 769$ & $9.3(6.7$ to 11.9$)$ & $16.4(9.8$ to 23.0$)$ & $11.8(7.0$ to 16.5$)$ & $1.9(0.5$ to 3.2$)$ \\
\hline Have sex once or more weekly & $158 / 493$ & $32.2(27.5$ to 36.9$)$ & $34.4(27.8$ to 41.0$)$ & 30.9 (23.2 to 38.6$)$ & $23.6(10.7$ to 36.5$)$ \\
\hline Positive physical quality of sex life & $372 / 522$ & $62.4(59.5$ to 65.3$)$ & $66.4(61.6$ to 71.3$)$ & 59.8 (54.8 to 64.8$)$ & $59.5(54.2$ to 64.7$)$ \\
\hline Positive emotional quality of sex life & $379 / 525$ & $62.3(59.3$ to 65.2$)$ & $63.7(58.8$ to 68.6$)$ & $61.0(56.0$ to 65.9$)$ & $61.8(56.7$ to 66.9$)$ \\
\hline Overall good quality of sex life & $322 / 522$ & 51.8 (48.8 to 54.8$)$ & 55.7 (50.6 to 60.9$)$ & $47.8(42.8$ to 52.8$)$ & 50.9 (45.6 to 56.2$)$ \\
\hline Interested in sex: & $253 / 1359$ & 21.2 (18.6 to 23.8 ) & 29.2 (24.3 to 34.2$)$ & 19.1 (15.1 to 23.2$)$ & $11.4(7.8$ to 15.0$)$ \\
\hline Living with partner & $180 / 684$ & 28.6 (24.7 to 32.5$)$ & $35.9(29.6$ to 42.1$)$ & 23.5 (17.4 to 29.5$)$ & $18.1(10.7$ to 25.5$)$ \\
\hline Not living with partner & $73 / 675$ & $10.6(7.9$ to 13.2$)$ & $12.0(6.2$ to 17.7$)$ & $13.3(8.4$ to 18.1$)$ & 7.0 (3.8 to 10.2$)$ \\
\hline
\end{tabular}

Numbers and percentage estimates are weighted to account for differential probabilities of selection and differential non-response.

${ }^{*}$ Number who answered question affirmatively of total number of respondents to question. Numbers of respondents varies within survey as some declined to answer some questions. 
groups reported having a partner, compared with $67.5 \%$ of women aged $25-54$ and fewer than $40 \%$ of women aged 75 and older. This finding reflects the longer life span of women, the age structure of marriage in the United States and other countries whereby men tend to marry younger women, and the higher proportion of older men with much younger partners. ${ }^{12728}$ As found by others, men and women with partners in middle and later life were equally likely to be sexually active, but the frequency of sexual activity declined across age groups for women more than for men. ${ }^{29}$ Many sexually active people in this study rated the quality of their sex life as less than good, including about half of sexually active older women. Particularly little has been known about the quality of older women's sexual lives.

Sexually active life expectancy was calculated as a function of gender and health. Overall, the study

Table $5 \mid$ Association with self rated health for selected measures of sexuality. Values are age adjusted odds ratios ( $95 \%$ confidence intervals)

\begin{tabular}{llclcr} 
Measures of & & Self rated health status, MIDUS & & \multicolumn{2}{c}{ Self rated health status, NSHAP } \\
\cline { 2 - 3 } $\begin{array}{l}\text { sexuality and } \\
\text { partnership } \dagger\end{array}$ & Good & $\begin{array}{c}\text { Very good or } \\
\text { excellent }\end{array}$ & & Good & $\begin{array}{r}\text { Very good or } \\
\text { excellent }\end{array}$
\end{tabular}

Partnership

\begin{tabular}{lcccc}
\hline Men & $1.2(0.78$ to 1.80$)$ & $1.1(0.76$ to 1.68$)$ & $1.4(0.96$ to 2.05$)$ & $1.8^{\star}$ (1.23 to 2.53$)$ \\
\hline Women & $0.9(0.61$ to 1.23$)$ & $1.2(0.61$ to 1.23$)$ & $1.7^{\star \star}(1.26$ to 2.39$)$ & $2.2^{\star \star \star}(1.60$ to 2.97$)$ \\
\hline Sexual activity & & & & \\
\hline Men & $2.0^{\star \star}(1.2$ to 3.1$)$ & $2.2^{\star \star}(1.4$ to 3.5$)$ & $2.5^{\star \star \star}(1.7$ to 3.6$)$ & $4.6^{\star \star \star}(3.2$ to 6.7$)$ \\
\hline Women & $0.8(0.5$ to 1.2$)$ & $1.6^{\star}(1.1$ to 2.3$)$ & $2.0^{\star \star \star}(1.4$ to 2.8$)$ & $2.8^{\star \star \star}(2.0$ to 3.9$)$ \\
\hline Living with partner: & & & & \\
\hline \multicolumn{1}{l}{ Men } & $2.3^{\star}(1.2$ to 4.5$)$ & $2.5^{\star \star}(1.3$ to 5.0$)$ & $2.3^{\star \star \star}(1.5$ to 3.7$)$ & $4.9^{\star \star \star}(3.2$ to 7.5$)$ \\
\hline Women & $0.8(0.4$ to 1.5$)$ & $1.9(1.0$ to 3.9$)$ & $2.1^{\star \star}(1.3$ to 3.5$)$ & $2.5^{\star \star \star}(1.6$ to 4.1$)$
\end{tabular}

Not living with

partner:

\begin{tabular}{lcccc} 
Men & $1.2(0.3$ to 3.9$)$ & $1.8(0.5$ to 5.6$)$ & $2.7^{\star \star}(1.3$ to 5.5$)$ & $3.8^{\star \star \star}(1.9$ to 7.5$)$ \\
\hline Women & $0.9(0.3$ to 2.7$)$ & $1.6(0.3$ to 2.7$)$ & $0.5(0.2$ to 1.2$)$ & $1.3(0.7$ to 2.6$)$
\end{tabular}

Having sex once or more weekly among sexually active

\begin{tabular}{|c|c|c|c|c|}
\hline Men & $1.5(0.9$ to 2.5$)$ & $1.6^{\star}(1.0$ to 2.6$)$ & 1.5 (0.9 to 2.7$)$ & $2.1^{\star \star}(1.2$ to 3.5$)$ \\
\hline Women & $1.3(0.8$ to 2.1$)$ & $1.4(0.9$ to 2.2$)$ & $1.1(0.6$ to 2.1$)$ & $1.4(0.8$ to 2.4$)$ \\
\hline \multicolumn{5}{|c|}{ Overall good quality sex life among sexually active } \\
\hline Men & $1.3(0.9$ to 2.0$)$ & $1.7^{\star}(1.1$ to 2.6$)$ & $1.1(0.7$ to 1.9$)$ & $1.4(0.8$ to 2.2$)$ \\
\hline Women & $1.1(0.8$ to 1.7$)$ & $1.7^{\star \star}(1.2$ to 2.5$)$ & $1.2(0.7$ to 2.2$)$ & $1.3(0.7$ to 2.2$)$ \\
\hline \multicolumn{5}{|c|}{ Interest in sex } \\
\hline Men & $1.3(0.9$ to 1.9$)$ & $1.4(1.0$ to 2.1$)$ & $1.2(0.8$ to 1.8$)$ & $1.7^{\star \star}(1.2$ to 2.4$)$ \\
\hline Women & $0.9(0.6$ to 1.3$)$ & $1.5^{*}(1.1$ to 2.2$)$ & $1.3(0.8$ to 2.0$)$ & $1.8^{*}(1.1$ to 2.7$)$ \\
\hline \multicolumn{5}{|c|}{ Living with partner: } \\
\hline Men & $1.1(0.7$ to 1.7$)$ & $1.3(0.9$ to 2.1$)$ & $1.1(0.7$ to 1.7$)$ & $1.5^{*}(1.0$ to 2.3$)$ \\
\hline Women & $1.1(0.7$ to 1.6$)$ & $1.6^{*}(1.1$ to 2.5$)$ & 1.0 (0.6 to 1.7$)$ & $1.0(0.6$ to 1.7$)$ \\
\hline
\end{tabular}

Not living with

partner:

\begin{tabular}{lcccc} 
Men & $2.3^{\star}(1.1$ to 4.9$)$ & $1.8(0.9$ to 3.7$)$ & $1.42(0.7$ to 3.0$)$ & $2.2^{\star \star}(1.1$ to 4.5$)$ \\
\hline Women & $0.7(0.4$ to 1.3$)$ & $1.3(0.7$ to 2.3$)$ & $1.5(0.6$ to 3.6$)$ & $4.2^{\star \star *}(1.9$ to 9.3$)$ \\
\hline
\end{tabular}

MIDUS=national survey of midlife development in the United States; NSHAP=national social life, health and ageing project.

${ }^{\star} \mathrm{P}<0.05 ;{ }^{* *} \mathrm{P}<0.01 ;{ }^{* * *} \mathrm{P}<0.001$.

Age adjusted odds ratios (95\% confidence intervals) are based on logistic regression, with age and self rated health status included as covariates. Estimates are obtained separately for men and women. The group

reporting poor or fair health was used as the reference. Confidence intervals are based on inversion of the Wald test constructed with use of design based standard errors.

†Respondents who were married or cohabiting at time of survey, even if they were not sexually active, were defined as having a partner.

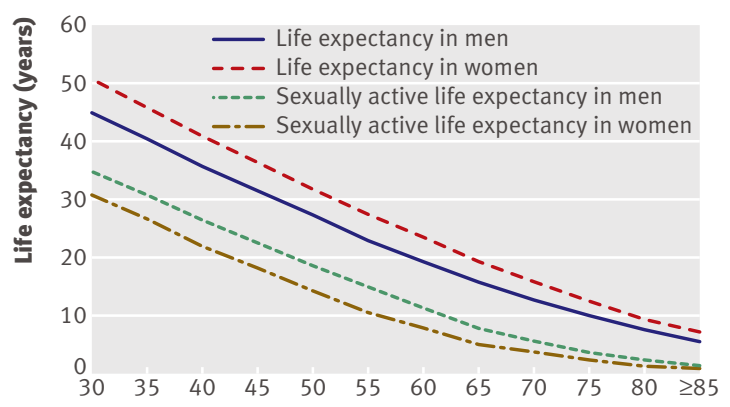

Age (years)

Fig 1| Life expectancy and sexually active life expectancy in US men and women. Based on data from national survey of midlife development in the United States (MIDUS)

found that men live a significantly greater proportion of their adult life as sexually active (due at least in part to more years of partnership than women) yet lose significantly more years of sexually active life as a result of poor health than do women. This resonates with findings from a previous analysis using the NSHAP dataset, showing that men's physical health problems were most commonly cited by both sexes as the reason for sexual inactivity in later life. ${ }^{1}$ The stronger association between sexually active life expectancy and health found in men may be explained in part by the effects of common chronic illnesses (for example, diabetes, cardiovascular disease, prostate cancer) and their treatments on erectile function. ${ }^{30-34}$ Loss of erectile function diminishes or prohibits penetrative intercourse and is often accompanied by a decline in or cessation of a man's sexual activity and sexual satisfaction. ${ }^{3536}$

In contrast, the effects of illness or drug use on sexual function in women are poorly understood. Sexual problems, including low desire, vaginal dryness, difficulties with orgasm, and pain with intercourse are prevalent among sexually active older women, ${ }^{1}$ are associated with decreased sexual satisfaction, ${ }^{35}$ but typically do not render a woman physically incapable of sexual intercourse. Women's sexual interest or motivation may be more resilient to illness or sexual problems than men's, ${ }^{37}$ may be more contextually dependent on the partner or situational factors, ${ }^{38}$ or, as seen in younger populations, older women may have less agency over their sexual activity than men. $^{38}$

Interest in sex among women of the same age in the two nationally representative cohorts surveyed 10 years apart was relatively stable. In contrast, significantly more men aged 57-64 in the later life cohort reported an interest in sex than men of the same age surveyed 10 years earlier. This was true for men with and without a partner in both cohorts and corroborates a positive secular trend in attitudes about sex found among older men surveyed 30 years apart in a 2001 study of 70 year olds in Gothenburg, Sweden. ${ }^{28}$ The difference may partly reflect the introduction of the highly effective and widely promoted male erectile dysfunction drugs to the US and European markets, 
Table $6 \mid$ Gender differences in sexually active life expectancy and proportion of remaining sexually active life, by partnership status and self rated health. Based on age specific prevalence estimates of sexual activity in national survey of midlife development in the United States (MIDUS) and national social life, health and ageing project (NSHAP) survey

\begin{tabular}{|c|c|c|c|c|}
\hline \multirow[b]{2}{*}{ Variables } & \multicolumn{2}{|c|}{ Sexually active life expectancy $(95 \% \mathrm{Cl})$} & \multicolumn{2}{|c|}{ Proportion of remaining sexually active life $(95 \% \mathrm{Cl})$} \\
\hline & Men & Women & Men & Women \\
\hline \multicolumn{5}{|l|}{ Age 30 years } \\
\hline \multicolumn{5}{|l|}{ MIDUS: } \\
\hline All & 34.7 (34.1 to 35.3) & 30.7 (30.0 to 31.4) & 77.5 (76.2 to 78.7$)$ & 60.7 (59.4 to 62.0$)$ \\
\hline Have partner & 36.7 (36.1 to 37.3$)$ & 38.2 (37.4 to 39.0$)$ & 81.9 (80.6 to 83.2$)$ & 75.5 (73.9 to 77.1$)$ \\
\hline \multicolumn{5}{|l|}{ Self rated health } \\
\hline Poor or fair & 30.9 (29.4 to 32.4$)$ & $29.1(27.5$ to 30.7$)$ & $69.0(65.6$ to 72.3$)$ & 57.5 (54.3 to 60.7$)$ \\
\hline Very good or excellent & 37.3 (36.5 to 38.1$)$ & 33.9 (32.9 to 34.9) & $83.3(81.4$ to 85.2$)$ & $67.0(64.9$ to 69.1$)$ \\
\hline \multicolumn{5}{|l|}{ Age 55 years } \\
\hline \multicolumn{5}{|l|}{ MIDUS: } \\
\hline All & $14.9(14.4$ to 15.4$)$ & 10.6 (10.0 to 11.2$)$ & $64.9(62.5$ to 67.1$)$ & 38.7 (36.5 to 40.9) \\
\hline Have partner & 15.9 (15.3 to 16.5$)$ & $15.6(14.8$ to 16.4$)$ & $69.1(66.7$ to 71.5$)$ & 56.9 (53.9 to 59.9) \\
\hline \multicolumn{5}{|l|}{ Self rated health } \\
\hline Poor or fair & 11.5 (10.3 to 12.7$)$ & 10.1 (8.9 to 11.3$)$ & $50.0(45.0$ to 55.0$)$ & 36.9 (32.4 to 41.3$)$ \\
\hline Very good or excellent & 16.9 (16.1 to 17.7$)$ & 12.9 (11.9 to 13.9$)$ & 73.5 (69.8 to 77.1$)$ & 47.1 (43.5 to 50.7$)$ \\
\hline \multicolumn{5}{|l|}{ NSHAP*: } \\
\hline All & 15.3 (14.8 to 15.8$)$ & 10.6 (10.0 to 11.2$)$ & $62.3(60.1$ to 64.5$)$ & 37.3 (35.1 to 39.5$)$ \\
\hline Have partner & 16.9 (16.2 to 17.6$)$ & $16.2(15.0$ to 17.4$)$ & 68.5 (65.7 to 71.3$)$ & 57.1 (52.7 to 61.5) \\
\hline \multicolumn{5}{|l|}{ Self rated health } \\
\hline Poor or fair & 11.2 (10.1 to 12.3$)$ & 7.1 (6.0 to 8.2$)$ & $45.6(41.2$ to 50.0$)$ & 25.1 (21.2 to 29.0) \\
\hline Very good or excellent & 18.0 (17.0 to 19.0$)$ & 12.7 (11.5 to 13.9$)$ & 73.4 (69.2 to 77.6$)$ & $44.9(40.7$ to 49.1$)$ \\
\hline
\end{tabular}

beginning with sildenafil in $1998 .{ }^{3940}$ More than $14 \%$ of US men surveyed in 2005-6 by NSHAP reported that they had taken prescription or non-prescription drugs or supplements to improve sexual function in the previous 12 months. ${ }^{1}$ With this secular increase in sexual interest among older men, the gender gap in later life interest in sex has also increased: among men aged 57 64 with partners, $76.7 \%$ reported an interest in sex compared with $35.9 \%$ of women with partners (only $12 \%$ of women without partners compared with $68 \%$ of men without partners were interested). Consistent with this finding, sexually active life expectancy at age 55 was longer for men surveyed in 2005-6 compared with men surveyed 10 years earlier $(4.8$ months longer overall, 12 months longer for men with

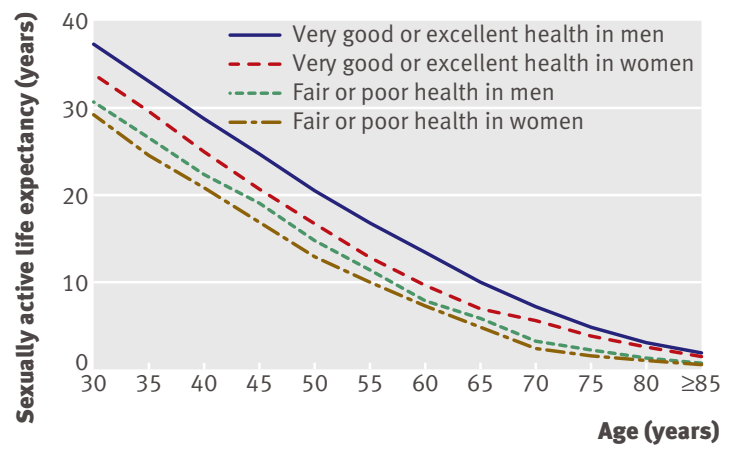

Fig 2 Sexually active life expectancy in US men and women by health status. Based on data from national survey of midlife development in the United States (MIDUS) partners), and increased only for women with a partner (7.2 month increase).

Strengths and limitations of the study

Although the data were collected by separate research groups using different sexuality measures, the use of two generally comparable population based probability samples for these analyses shows external validity of the study findings and made it possible to create the new sexually active life expectancy measure. Prevalence estimates for partnership, sexual activity, sexual frequency, and good quality sex life were highly consistent when the overlapping age groups in the two studies were compared and are consistent with previous findings for men $^{41}$ and younger women. ${ }^{4243}$ In addition, use of the two datasets allowed examination of secular trends in various aspects of sexuality measured 10 years apart. Comparison with the 1971 and 2001 Swedish studies of 70 year olds provides additional evidence of external validity of the cross sectional and secular trend findings. For example, the 2001 Swedish study found similar frequencies of sexual activity and satisfaction among women with and without partners as found in the 2005-6 US cohort. These frequencies were higher than those found in the 1995-6 US cohort of 65-74 year olds and notably higher than in the 1971 Swedish cohort of 70 year olds. ${ }^{28}$

Longitudinal data are needed to determine whether regular sexual activity, a good sex life, or high sexual interest promote health or whether good health promotes these positive sexual attributes; this study relies 


\section{WHAT IS ALREADY KNOWN ON THIS TOPIC}

Many older people are sexually active

Partnership and sexual activity have been positively associated with health in middle age and later life

Knowledge about patterns of sexual activity in the population informs public health policy and patient education and counselling

\section{WHAT THIS STUDY ADDS}

Frequency of sexual activity, a good quality sex life, and interest in sex are positively associated with health in middle age and later life

Interest in sex among middle aged and older men in the United States has increased since 2000

About half of sexually active older women report a poor quality sex life

At age 55, sexually active life expectancy is 15 years for men and 10.6 years for women; although the period is longer for men, they lose more years of sexually active life as a result of poor health than women
In this study we assumed the same mortality for people with different health and partnership statuses. This assumption might underestimate sexually active life expectancy for those with very good or excellent health or for those with a partner and might overestimate sexually active life expectancy for those with poor or fair health owing to the possibility of differential survival among people with different health statuses and partnership. ${ }^{48}$ Our analytical approach used official life tables to predict mortality accurately but was limited by the lack of accessible and reliable age and gender specific estimates of survival by health and partnership status.

\section{Conclusions and policy implications}

Sexual partnership, frequency of sexual activity, a good quality sex life, and interest in sex are positively associated with health among middle aged and older adults in the United States. Interest in sex among middle aged and older men in the United States has increased since 2000. Overall, the study found that men have a longer sexually active life expectancy and that most sexually active men report a good quality sex life. In contrast, only about half of sexually active women reported a good quality sex life. This disparity, and its implication for health, requires further exploration.

Men lose more years of sexually active life as a result of poor health than women. The estimation of sexually active life expectancy is a new life expectancy tool that can be used for projecting public health and patient needs in the arena of sexual health. Projecting the population patterns of sexual activity in later life is useful for anticipating need for public health resources, expertise, and medical services. Translation of expectations about the duration and quality of sexually active life may, at the individual level, influence important health behaviours to promote or prolong sexual functioning, such as adherence to medical treatment or maintenance of a healthy lifestyle. One study found that parents of children with cancer exhibited different medical decision making and healthcare utilisation when they had more accurate expectations of their child's life expectancy. ${ }^{50}$ Further research is needed to evaluate the potential impact of sexually active life expectancy projection on individual health behaviour.

We thank Andreea Mihai, Jessica Schwartz, and Katherine Githens for research assistance. Their effort was supported by funding received for the Center on Demography and Economics of Aging Chicago Core on Biomarkers in Population-Based Health and Aging Research from the National Institutes of Health/National Institute on Aging (5P30 AG 012857) and institutional resources from the University of Chicago. Contributors: Both authors originated and designed the study, interpreted the results, commented on drafts of the article, and act as guarantors. NG carried out the statistical analyses and calculations.

Funding: This study was partially supported by the National Institute on Aging/Rutgers University pilot award, the University of Chicago Population Research Centre pilot grant (NIH/NICHD R24 HD051152-01), the University of Chicago Centre on Demography and Economics of Aging pilot grant (NIH/NIA 5P30 AG 012857), and Population Research Centre grant from the National Institute of Child Health and Human Development (R24 HD051152-04). NG was supported by, and STL partially supported by, the National Institutes of Health, National Institute on Aging University of Chicago-NORC Centre on Demography and Economics of Aging Core 
on Biomarkers in Population-Based Health and Aging Research (5 P30 AG 012857). STL was also supported by 1K23AG032870-01A1. The funders had no role in the study design. The authors retained full independence in the collection (NSHAP), analysis, and interpretation of the data (NSHAP and MIDUS), the writing of this report, and in the decision to submit this article for publication. The authors were not involved in the collection of the MIDUS data.

Competing interests: All authors have completed the Unified Competing Interest form at http://www.icmje.org/coi_disclosure.pdf (available on request from the corresponding author) and declare that (1) no company has had involvement in the submitted work; (2) no authors have relationships with any companies that might have an interest in the submitted work in the previous 3 years; (3) their spouses, partners, or children have no financial relationships that may be relevant to the submitted work; and (4) no authors have any non-financial interests that may be relevant to the submitted work.

Ethical approval: The NSHAP data analysis was carried out under expedited approval from the University of Chicago institutional review board (No 16950A, 4/24/09). The MIDUS data analysis was carried out under exempt protocol from the University of Chicago institutional review board (No 13996E, 6/2/05). This research was carried out with deidentified, publicly available data with approval of the University of Chicago institutional review board. For neither study did the authors have access to any personally identifiable information or information that would link the data to individuals' identities. All data are reported in aggregate to eliminate the possibility of deductive identification of individuals.

Data sharing: Data for the National Social Life Health and Aging Project are available at www.icpsr.umich.edu/NACDA/news.html\#nshap. Data for the MIDUS study are available to researchers at webapp.icpsr.umich. edu/icpsrweb/ICPSR/studies/02760. Calculation of sexually active life expectancy used publicly available life tables and the Excel spreadsheet available at http://reves.site.ined.fr/en/resources/computation_online/ sullivan/. Statistical codes are available from NG at ngavrilova@babies.bsd.uchicago.edu.

1 Lindau ST, Schumm P, Laumann EO, Levinson W, O'Muircheartaigh C, Waite L. A national study of sexuality and health among older adults in the US. N Engl J Med 2007;357:22-34.

2 Satcher $D$. The surgeon general's call to action to promote sexual health and responsible sexual behaviour. US Department of Health and Human Services, 2001.

3 World Health Organization. Defining sexual health: report of a technical consultation on sexual health, 28-31 January 2002. Geneva, 2002. www.who.int/reproductivehealth/topics/ gender_rights/defining_sexual_health/en/index.html.

4 Onder G, Penninx B, Guralnik JM, Jones H, Fried LP, Pahor M, et al. Sexual satisfaction and risk of disability in older women. J Clin Psychiatry 2003;64:1177-82.

5 Davey Smith G, Frankel S, Yarnell J. Sex and death: are they related? Findings from the Caerphilly Cohort Study. BMJ 1997;315:1641-4.

6 Palmore EB. Predictors of the longevity difference: a 25-year followup. Gerontologist 1982;22:513-8.

7 Laumann EO, Nicolosi A, Glasser DB, Paik A, Gingell C, Moreira E, et al. Sexual problems among women and men aged 40-80 y: prevalence and correlates identified in the Global Study of Sexual Attitudes and Behaviors. Int J Impotence Res 2005;17:39-57.

8 United Nations. World population ageing 2007. UN, 2007.

9 Brim OG, Ryff CD, Kessler RC. The MIDUS National Survey: an overview. How healthy are we? A national study of well-being at midlife. University of Chicago Press, 2004.

10 Mossey EJMS. Self-rated health: a predictor of mortality among the elderly. Am J Public Health 1982;72:800-8.

11 Schoenfeld DE, Malmrose LC, Blazer DG, Gold DT, Seeman TE. Selfrated health and mortality in the high-functioning elderly-a closer look at healthy individuals: MacArthur Field Study of Successful Aging. J Gerontol (A Medical Sciences) 1994;49:109-15M.

12 Laumann EO, Michael RT. Sex, love, and health in America: private choices and public policies. University of Chicago Press, 2000.

13 Smith S, Jaszczak A, Graber J, Lundeen K, Leitsch S, Wargo E, et al. Instrument development, study design implementation, and survey conduct for the National Social Life, Health, and Aging Project. J Gerontol (B Psychol Sci Soc Sci) 2009;64:20-91.

14 Hosmer DW, Lemeshow S. Applied logistic regression. Wiley, 1989.

15 Binder D. On the variances of asymptotically normal estimators from complex surveys. Int Stat Rev 1983;51:279-92.

16 Crimmins EM, Saito Y. Trends in healthy life expectancy in the United States, 1970-1990: gender, racial, and educational differences. Soc Sci Med 2001;52:1629-41.
17 Cambois E, Robine JM, Hayward MD. Social inequalities in disabilityfree life expectancy in the French male population, 1980-1991. Demography 2001;38:513-24.

18 Guralnik JM, Land KC, Blazer D, Fillenbaum GG, Branch LG. Educational status and active life expectancy among older blacks and whites. N Engl J Med 1993;329:110-6.

19 Hayward MD, Heron M. Racial inequality in active life among adult Americans. Demography 1999;36:77-91.

20 Nusselder WJ, Looman CW, Mackenbach JP, Huisman M, van Oyen H, Deboosere $P$, et al. The contribution of specific diseases to educational disparities in disability-free life expectancy. Am J Public Health 2005;95:2035-41.

21 Wilkins R, Adams OB. Health expectancy in Canada, late 1970s: demographic, regional, and social dimensions. Am J Public Health 1983;73:1073-80

22 Jagger C. Health expectancy calculation by the Sullivan method: a practical guide. European concerted action on the harmonization of health expectancy calculations in Europe. Nihon University Population Research Institute research paper series No 68. NUPRI, 1999.

23 Sullivan DF. A single index of mortality and morbidity. HSMHA Health Reports 1971;86:347-54

24 Human Mortality Database. 2008. www.mortality.org.

25 US Census Bureau. Census 2000. PHC-T-26. Population in group quarter by type, sex and age, for the United States: 1990-2000. 2000. www.census.gov/population/www/cen2000/briefs/phc-t26/

26 Decker FH. Nursing homes, 1977-1999: what has changed, what has not? National Center of Health Statistics, 2005.

27 Carpenter LM, Nathanson CA, Kim YJ. Sex after 40? gender, ageism, and sexual partnering in midlife. J Aging Stud 2006;20:93-106.

28 Beckman N, Waern M, Gustafson D, Skoog I. Secular trends in self reported sexual activity and satisfaction in Swedish 70 year olds: cross sectional survey of four populations, 1971-2001. BMJ 2008;337:151-4.

29 Diokno AC, Brown MB, Herzog AR. Sexual function in the elderly. Arch Intern Med 1990;150:197-200.

30 Burke JP, Jacobson DJ, McGree ME, Nehra A, Roberts RO, Girman CJ, et al. Diabetes and sexual dysfunction: results from the Olmsted County study of urinary symptoms and health status among men. J Urol 2007;177:1438-42.

31 Solomon H, Man JW, Jackson G. Erectile dysfunction and the cardiovascular patient: endothelial dysfunction is the common denominator. Heart 2003;89:251-3.

32 Westlake C, Dracup K, Walden JA, Fonarow G. Sexuality of patients with advanced heart failure and their spouses or partners. J Heart Lung Transplant 1999;18:1133-8.

33 Heiman JR. Sexual dysfunction: ovenview of prevalence, etiological factors, and treatments. J Sex Res 2002;39:73-8.

34 Laumann EO, Paik A, Rosen RC. Sexual dysfunction in the United States—prevalence and predictors. JAMA 1999;281:537-44.

35 Carpenter LM, Nathanson CA, Kim YJ. Physical women, emotional men: gender and sexual satisfaction in midlife. Arch Sex Behav 2009;38:87-107.

36 Fisher WA, Meryn S, Sand M, Brandenburg U, Buvat J, Mendive J, Scott $\mathrm{S}$, et al. Communication about erectile dysfunction among men with ED, partners of men with ED, and physicians: the Strike Up a Conversation Study (Part I). J Men's Health and Gender 2005;2:64-78.

37 Grimm RH Jr, Grandits GA, Cutler JA, Stewart AL, McDonald RH, Svendsen K, et al. Relationships of quality-of-life measures to longterm lifestyle and drug treatment in the Treatment of Mild Hypertension Study. Arch Intern Med 1997;29:8-14.

38 Hartmann U, Philippsohn S, Heiser K, Ruffer-Hesse C. Low sexual desire in midlife and older women: personality factors, psychosocia development, present sexuality. Menopause 2004;11:726-40.

39 US Food and Drug Administration. Drug details: Viagra. Washington, DC, 2009.

40 European Medicines Agency. EPAR for authorised medicinal products for human use, 2009. www.ema.europa.eu/humandocs/ Humans/EPAR/SildenafilActavis/SildenafilActavis.htm.

41 Gray AF, Henry A, McKinlay JB, Longcope C. Age, disease, and changing sex hormone levels in middle-aged men: results of the Massachusetts Male Aging Study. J Clin Endocrinol Metab 1991;73:1016-25.

42 Avis NE, Brockwell S, Randolph JF, Shen SH, Cain VS, Ory M, et al. Longitudinal changes in sexual functioning as women transition through menopause: results from the Study of Women's Health Across the Nation. Menopause 2009;16:442-52.

43 Matthias REL, James E, Atchison KA, Schweitzer SO. Sexual activity and satisfaction among very old adults: results from a communitydwelling Medicare population survey. Gerontologist 1997;37:6-14

44 Cantania JA, Gibson DR, Chitwood DD, Coates TJ. Methodological problems in AIDS behavioral research: influences on measurement 
error and participation bias in studies of sexual behavior. Psychol Bull 1990;108:339-62.

45 Fenton KA, Johnson AM, McManus S, Erens B. Measuring sexual behaviour: methodological challenges in survey research. Sex Transm Inf 2001;77:84-92.

46 Palloni A. Increment-decrement life tables. In: Preston SH, Heuveline P, Guillot M, eds. Demography: measuring and modeling population processes. Blackwell, 2001.

47 Mathers CD, Robine JM. How good is Sullivan's method for monitoring changes in population health expectancies? Reply. J Epidemiol Community Health 1997;51:578-9.
48 Ford J, Spallek M, Dobson A. Self-rated health and a healthy lifestyle are the most important predictors of survival in elderly women. Age Ageing 2008;37:194-200.

49 Mossey JM, Shapiro E. Self-rated health—a predictor of mortality among the elderly. Am J Public Health 1982;72:800-8.

50 Wolfe NJK, Grier HE, Duncan J, Salem-Schatz S, Emanuel EJ, Weeks JC. Understanding of prognosis among parents of children who died of cancer: impact on treatment goals and integration of palliative care. IAMA 2000;284:2469-75.

Accepted: 22 December 2009 